\title{
Improvement of Vacuum-Ultraviolet Transparency of Silica Glass by Modification of Point Defects
}

\author{
Koichi KAJIHARA \\ Transparent Electro-Active Materials Project, ERATO-SORST, Japan Science and Technology Agency, \\ in Frontier Collaborative Research Center, Mail Box S2-13, Tokyo Institute of Technology, \\ 4259, Nagatsuta, Midori-ku, Yokohama-shi 226-8503
}

\begin{abstract}
Silica glass is an important optical material in deep-ultraviolet (DUV, $\lambda \lesssim 300 \mathbf{n m}$ ) and vacuum-ultraviolet $(V U V, \lambda \lesssim 200 \mathrm{~nm})$ spectral regions. However, DUV-VUV transparency of silica glass is significantly influenced by the presence of structural imperfections (point defects). This article describes point defects in silica glasses of low metallic impurity contents ("synthetic" silica glasses), and optical and chemical properties of these point defects. It is shown that controlled doping with specific point defects can improve the transparency and radiation hardness of silica glass in DUV-VUV spectral region. Such doped species include network modifiers that relax the glass structure and mobile interstitial hydrogen molecules. Utilization of these techniques in developing photomask substrates for $F_{2}$ laser photolithography and DUV optical fibers for ArF laser transmission is presented.
\end{abstract}

[Received October 2, 2006]

Key-words : Silica glass, Transparency, Point defects, Deep ultraviolet, Vacuum ultraviolet, Excimer laser

\section{Introduction}

D EEP-ULTRAVIOLET (DUV) and vacuum-ultraviolet (VUV) spectral ranges refer to wave-lengths shorter than $\sim 300 \mathrm{~nm}$ and $\sim 200 \mathrm{~nm}$, respectively. DUV-VUV light sources, in particular excimer lasers such as $\mathrm{KrF}(h v=5.0 \mathrm{eV}$, $\lambda=248 \mathrm{~nm}), \operatorname{ArF}(h v=6.4 \mathrm{eV}, \lambda=193 \mathrm{~nm})$, and $\mathrm{F}_{2}(h v=7.9$ $\mathrm{eV}, \lambda=157 \mathrm{~nm}$ ) lasers, become increasingly important in photolithography, laser processing, and photochemical reactions. Figure 1 shows optical absorption spectra of silica glass from infrared (IR) to VUV spectral region. ${ }^{1)}$ Silica glass is one of the most important optical materials at DUV-VUV spectral region because the shape workability is good and the DUV-VUV transparency is the best among commercial optical glasses currently available.

In general, silica glasses for optical applications are prepared by vapor-phase methods. This type of silica glass is often referred to as "synthetic silica glass" and the concentration of metallic impurities is very low. As a consequence, IR transmittance of synthetic silica glasses becomes high enough to realize the optical fiber telecommunication. However, the DUV-VUV transmittance of synthetic silica glass is often far

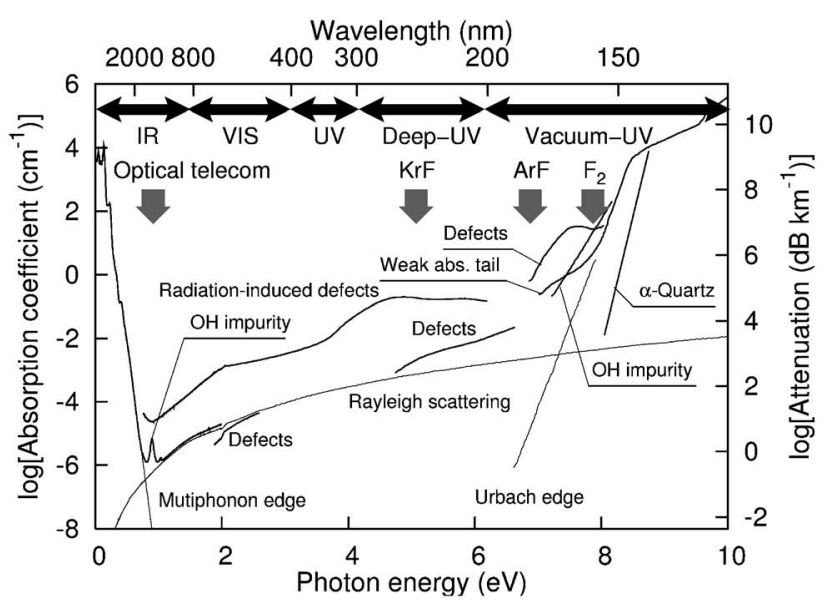

Fig. 1. Optical absorption spectra of silica glass and $\alpha$-quartz (adapted from Ref. [1] with permission). from the theoretical limit determined by the Rayleigh scattering and the Urbach absorption edge. ${ }^{1), 2)}$ The transmission loss originates from structural imperfections in silica glass ("point defects"), which are formed during the manufacturing processes or generated later by photoinduced reactions. However, scientific understanding of point defects has been insufficient in fabricating silica glasses with good transmittance and hardness to DUV-VUV laser light.

This article is intended to outline DUV-VUV optical properties and chemical reactivities of point defects found in synthetic silica glasses currently available, and to describe ways to improve the DUV-VUV transparency of silica glass by modification of point defects.

\section{Optical and chemical properties of point defects in synthetic silica glass}

A. Strained Si-O-Si bonds

Silica glass is an amorphous material and its atomic configuration is disordered. Studies by X-ray diffraction ${ }^{3)}$ and nuclear magnetic resonance ${ }^{4}$ have indicated that the main origin of the disorder is the distribution of the bridging angle between two $\mathrm{SiO}_{4}$ tetrahedra ( $\mathrm{Si}-\mathrm{O}-\mathrm{Si}$ angle). In contrast, deformation of the $\mathrm{SiO}_{4}$ tetrahedra is relatively small. These characteristics are well reproduced by a silica structure constructed by molecular dynamics calculations. ${ }^{5), 6)}$ Figure 2 shows distributions of $\mathrm{Si}-\mathrm{O}-\mathrm{Si}$ angles, $\mathrm{O}-\mathrm{Si}-\mathrm{O}$ angles, and $\mathrm{Si}-\mathrm{O}$ bond lengths in this model structure. Compared to the $\mathrm{Si}-\mathrm{O}-\mathrm{Si}$ bonds at the central part of the distribution, those belonging to the tail parts are much more strained and termed "strained Si-O-Si bonds".

$\alpha$-quartz is a crystalline silica polymorph. Similarly to silica glass, it also consists of $\mathrm{SiO}_{4}$ tetrahedra connected at their corners into a three-dimensional network. However, Si-O-Si bonds in $\alpha$-quartz have nearly the same angle and are not strained. The VUV absorption edge of $\alpha$-quartz is located at higher energy than that of silica glass (Fig. 1). .) The VUV absorption edge of silica glass is shifted to lower energy by high-pressure densification, ${ }^{8)}$ which decreases the average $\mathrm{Si}-\mathrm{O}-\mathrm{Si}$ angle. ${ }^{9)}$ The distribution of $\mathrm{Si}-\mathrm{O}-\mathrm{Si}$ angle is more gently modified by thermal annealing. ${ }^{10)}$ The VUV absorption edge of silica glass is shifted to lower energy with an increase in fictive temperature from 900 to $1400^{\circ} \mathrm{C}$. This change is 

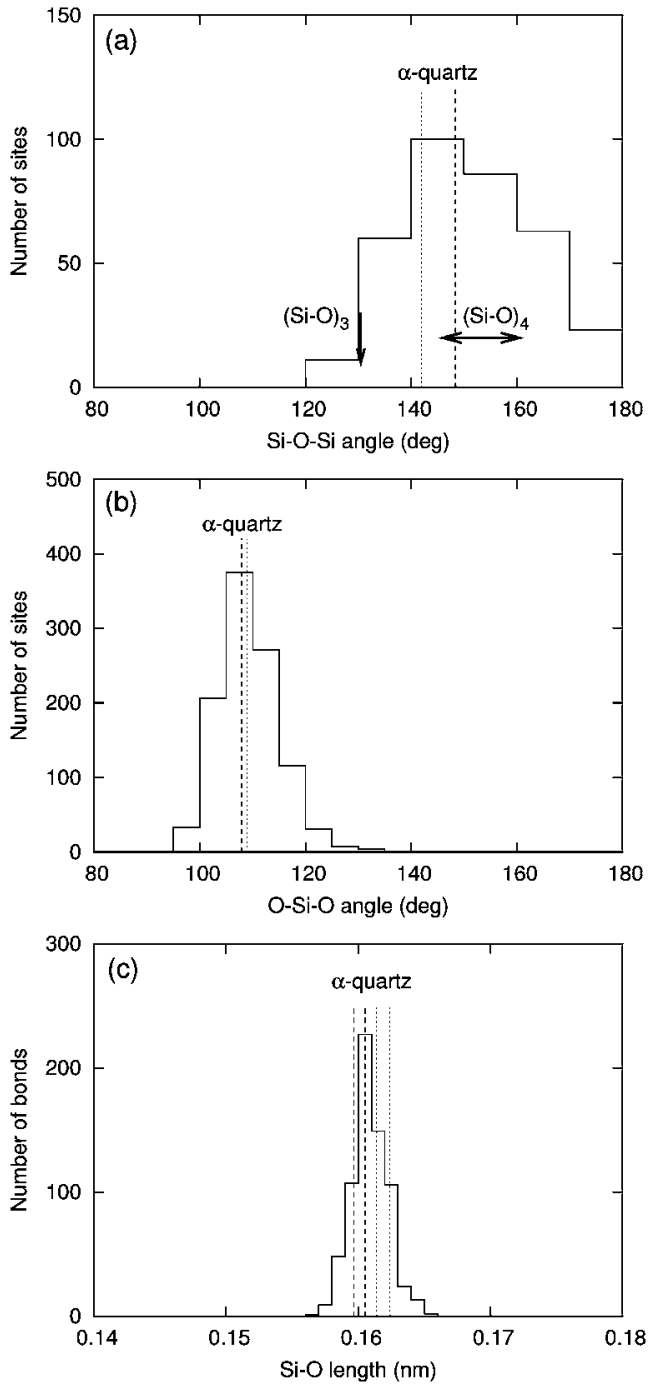

Fig. 2. Distributions of $\mathrm{Si}-\mathrm{O}-\mathrm{Si}$ angle (a), O-Si-O angle (b), and $\mathrm{Si}-\mathrm{O}$ length in a silica structure consisting of 648 atoms. The structure is obtained by periodic classical molecular dynamics calculations. ${ }^{5), 6}$ The maxima of the distributions are located very close to the values of an $\alpha$-quartz structure calculated using the same set of inter-atomic potentials (dashed lines). The experimentally determined values of $\alpha$-quartz are also shown by dotted lines. Thick arrows indicate $\mathrm{Si}-\mathrm{O}-\mathrm{Si}$ angles of small ring structures $\left[(\mathrm{Si}-\mathrm{O})_{n}\right.$ where $n=3$ and 4$]$ in silica glass. ${ }^{12)}$ The $n=3$ ring is nearly planar with an $\mathrm{Si}-\mathrm{O}-\mathrm{Si}$ angle at $\sim 130^{\circ}$, whereas the $n=4$ ring can be puckered with decreasing the $\mathrm{Si}-\mathrm{O}-\mathrm{Si}$ angle from the planar value $\left(\sim 160^{\circ}\right)$.

concurrent to the decrease in the average $\mathrm{Si}-\mathrm{O}-\mathrm{Si}$ angle and concentration increase in small ring structures $(\mathrm{Si}-\mathrm{O})_{n}$ where $n=3$ and $4 .{ }^{10), 11)}$ These small rings are typical strained bonds that are directly detectable by Raman spectroscopy, ${ }^{12)}$ and are not present in $\alpha$-quartz consisting of the $n=6$ and 8 rings. These observations indicate that the strained $\mathrm{Si}-\mathrm{O}-\mathrm{Si}$ bonds are responsible for the optical absorption near the VUV absorption edge of silica glass.

Cleavage of $\mathrm{Si}-\mathrm{O}$ bond,

$$
\equiv \mathrm{Si}-\mathrm{O}-\mathrm{Si} \equiv \stackrel{h v}{\longrightarrow} \equiv \mathrm{SiO} \cdot+\cdot \mathrm{Si} \equiv,
$$

is a dominant origin of the radiation-induced point defects in silica glass. ${ }^{11,13)-16)}$ It is likely that the strained $\mathrm{Si}-\mathrm{O}-\mathrm{Si}$ bonds are primarily cleaved because the formation of X- and $\gamma$-rayinduced dangling bonds $\left(E^{\prime}\right.$ center, $\equiv \mathrm{Si}^{*}$, and non-bridging

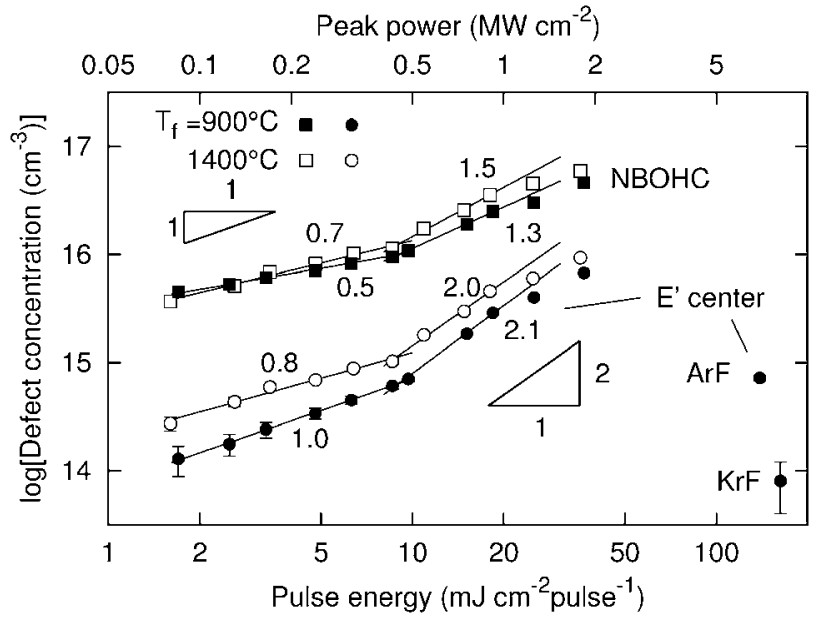

Fig. 3. Dependence of the photoinduced concentrations of $E^{\prime}$ center and $\mathrm{NBOHC}$ on pulse energy of $\mathrm{F}_{2}$ laser. ${ }^{18), 19)}$ Concentrations of $\mathrm{KrF}$ and ArF-laser-induced $E^{\prime}$ centers are also shown. Fictive temperature of the samples are set at 900 or $1400^{\circ} \mathrm{C}$. All samples are exposed to $3 \times$ $10^{4}$ laser pulses.

oxygen hole center, $\mathrm{NBOHC}, \equiv \mathrm{SiO}^{*}$ ) are enhanced both by the high-pressure densification ${ }^{17)}$ and by increasing fictive temperature. ${ }^{16)} \mathrm{F}_{2}$ laser light interacts with the strained SiO-Si bonds more directly: it excites the VUV absorption of the strained $\mathrm{Si}-\mathrm{O}-\mathrm{Si}$ bonds and causes reaction Eq. (1) via onephoton absorption processes, as shown in Fig. 3. ${ }^{11), 18), 19)}$ Furthermore, at large $\mathrm{F}_{2}$ laser pulse energies this reaction turns into a two-photon process, which is most likely due to twostep absorption via real intermediate states. ${ }^{18), 19)}$ As a consequence, this $\mathrm{F}_{2}$-laser-induced two-photon process is much more efficient than the same reaction caused by simultaneous two-photon absorption of $\mathrm{KrF}$ or ArF laser light, which does not directly excite the VUV absorption band of strained $\mathrm{Si}-\mathrm{O}-\mathrm{Si}$ bonds.

$E^{\prime}$ centers have an intense optical absorption band at $5.8 \mathrm{eV}$, and NBOHCs exhibit two optical absorption bands of comparable intensities at 4.8 and $\sim 6.5 \mathrm{eV}$. These absorption bands significantly reduce the DUV-VUV transmittance of synthetic silica glasses. The $6.5 \mathrm{eV}$ absorption band of NBOHC has been identified recently both by experimen$\mathrm{tal}^{20), 21)}$ and theoretical ${ }^{22)}$ studies.

\section{B. Network modifiers}

Although the concentrations of the metallic impurities are very small, synthetic silica glasses contain a small amount of non-metallic impurities originating from chemical compounds used for the manufacturing. The main impurities are hydrogen, fluorine, and chlorine atoms. These elements are monovalent and serve as network modifiers that break up the glass network.

Hydroxyl group ( $\mathrm{SiOH})$ is the most common network modifiers in synthetic silica glasses. It is incorporated in silica glasses while hydrolyzing silane-based precursor gas molecules in oxygen-hydrogen combustion flame. $\mathrm{SiOH}$ groups exhibit a characteristic IR absorption band at $\sim 3670 \mathrm{~cm}^{-1}$, which is associated with the SiO-H stretching mode. This IR absorption band undergoes a low energy shift when the bonding configuration of $\mathrm{SiOH}$ groups is altered from isolated free state to hydrogen-bonded state ${ }^{23), 24)}$ by cooling, ${ }^{25)} \mathrm{F}_{2}$ laser irradiation, ${ }^{26)}$ heavy exposure to $\gamma$-rays, ${ }^{27)}$ or by increasing the fictive temperature. ${ }^{28)}$

$\mathrm{SiOH}$ groups exhibit a VUV optical absorption band above 
$\sim 7.3 \mathrm{eV} .{ }^{25)}$,29)-32) This absorption band is shifted to higher energy along with the structural alternation of $\mathrm{SiOH}$ groups from the isolated to the hydrogen-bonded states. ${ }^{25), 26)}$ Isotope exchange of $\mathrm{H}$ with $\mathrm{D}$ causes a high energy shift almost equal to the difference in the zeroth vibrational levels between the $\mathrm{O}-\mathrm{H}$ and $\mathrm{O}-\mathrm{D}$ oscillators $(\sim 0.06 \mathrm{eV})$, indicating that the potential surface of the excited state is dissociative against the stretching of $\mathrm{O}-\mathrm{H}$ bond. ${ }^{32}$ Hence, direct VUV photoexcitation of $\mathrm{SiOH}$ groups results in an efficient photolysis of the $\mathrm{SiO}-\mathrm{H}$ bond (quantum yield $\sim 0.1-0.2$ ) to form a pair of $\mathrm{NBOHC}$ and mobile hydrogen atom $\left.\left.\left(\mathrm{H}^{0}\right), 33\right)-35\right)$

$$
\equiv \mathrm{SiO}-\mathrm{H} \stackrel{h v}{\longrightarrow} \equiv \mathrm{SiO}^{\bullet}+\mathrm{H}^{0} .
$$

Hydride $(\mathrm{SiH})$ group is another form of hydrogen bound to the silica network. Optical properties of $\mathrm{SiH}$ groups remain elusive. It is likely that the optical transition of $\mathrm{SiH}$ groups is located at higher energy than the absorption edge of silica glass $^{36), 37)}$ and its DUV-VUV absorption is very weak. ${ }^{38)}$ On the other hand, there are suggestions that the $\mathrm{Si}-\mathrm{H}$ bonds are photolyzed by DUV-VUV laser light, ${ }^{39)-41)}$

$$
\equiv \mathrm{Si}-\mathrm{H} \stackrel{h v}{\longrightarrow} \equiv \mathrm{Si}^{\bullet}+\mathrm{H}^{0} \text {. }
$$

Fluorine and chlorine atoms originate from the silane precursor compounds such as $\mathrm{SiCl}_{4}$ and $\mathrm{SiF}_{4}$ as well as dehydration agents such as $\mathrm{Cl}_{2}, \mathrm{SOCl}_{2}, \mathrm{CCl}_{4}$, and $\mathrm{CF}_{4}$ used to remove $\mathrm{SiOH}$ groups. They attach to a network silicon atom with replacing one of the four bridging oxygen atoms, and thus form chloride $(\mathrm{SiCl})$ and fluoride $(\mathrm{SiF})$ groups. However, an NMR study has shown that in heavily fluorinedoped silica glasses ( $\mathrm{SiF} 3$ mass\%), a part of silicon atoms can be five-coordinated with one fluorine and four bridging oxygen atoms. ${ }^{42)} \mathrm{SiF}$ groups are detectable via their characteristic Raman band at $945 \mathrm{~cm}^{-1},{ }^{43)-46)}$ whereas selective detection of $\mathrm{SiCl}$ groups is difficult.

$\mathrm{SiCl}$ groups undergo various chemical reactions with reactive molecules incorporated in interstitial voids of silica glasses by thermal annealing. $\mathrm{SiCl}$ groups generate interstitial $\mathrm{Cl}_{2}$ and $\mathrm{HCl}$ molecules,

$$
\begin{aligned}
2 & \equiv \mathrm{SiCl}+1 / 2 \mathrm{O}_{2} \longrightarrow \equiv \mathrm{Si}-\mathrm{O}-\mathrm{Si} \equiv+\mathrm{Cl}_{2}, \\
& \equiv \mathrm{SiCl}+\mathrm{H}_{2} \mathrm{O} \longrightarrow \equiv \mathrm{SiOH}+\mathrm{HCl},
\end{aligned}
$$

through reactions with interstitial $\mathrm{O}_{2}$ and $\mathrm{H}_{2} \mathrm{O}$ molecules, respectively. ${ }^{47)}$

It is considered that $\mathrm{SiCl}$ group is a main source of radiation-induced point defects because the concentrations of radiation-induced defects in chlorine-doped silica glasses are generally larger than those in chlorine-free glasses. ${ }^{48)}{ }^{49)} \mathrm{H}^{0} \mathrm{~s}$ created via Eq. (2) convert $\mathrm{SiCl}$ groups to $E^{\prime}$ centers and $\mathrm{HCl}$ molecules, ${ }^{47)}$

$$
\equiv \mathrm{SiCl}+\mathrm{H}^{0} \longrightarrow \equiv \mathrm{Si}^{\bullet}+\mathrm{HCl} \text {. }
$$

By analogy, chlorine-related radicals $\left(\mathrm{ClO}_{x}\right.$ where $\left.x=2,3\right)$ are formed in $\mathrm{F}_{2}$-laser-irradiated silica glasses containing both $\mathrm{SiCl}$ groups and interstitial oxygen molecules $\left(\mathrm{O}_{2}\right) .^{50)}$ This reaction would be due to cracking of $\mathrm{SiCl}$ groups with oxygen atoms $\left(\mathrm{O}^{0}\right)$ generated by the $\mathrm{F}_{2}$ laser photolysis of $\mathrm{O}_{2}$. In addition, resultant interstitial $\mathrm{Cl}_{2}, \mathrm{HCl}$, and $\mathrm{ClO}_{x}$ would be further decomposed by DUV-VUV light to participate in secondary reactions.

Controversy still remains concerning the photoinduced defect formation from $\mathrm{SiCl}$ groups. $\mathrm{A} \mathrm{Si}-\mathrm{Cl}$ bond is dissociated by X-and $\gamma$-rays to form a pair of $E^{\prime}$ center and a chlorine atom $\left(\mathrm{Cl}^{0}\right) .{ }^{15), 51)}$ The formation of $\mathrm{Cl}^{0}$, however, is not observed in a chlorine-doped silica glass exposed to $\mathrm{F}_{2}$ laser light at $77 \mathrm{~K},{ }^{47)}$ although $\mathrm{F}_{2}$ laser light directly excites a weak
VUV optical absorption band of $\mathrm{SiCl}$ groups above $\sim 7.5 \mathrm{eV}{ }^{52)}$ Some chlorine-doped silica glasses even show better hardness to ArF laser light than chlorine-free silica glasses. ${ }^{53)}$ These observations may indicate that $\mathrm{SiCl}$ groups show a good stability to DUV-VUV light in the absence of interstitial chemical species.

$\mathrm{SiF}$ groups do not exhibit measurable optical absorption within the band gap of silica glass ${ }^{46), 54), 55)}$ and are much more stable than $\mathrm{SiCl}$ groups. These properties primarily originate from the large $\mathrm{Si}-\mathrm{F}$ bonding energy, which is even larger than the $\mathrm{Si}-\mathrm{O}$ bonding energy. In contrast to $\mathrm{SiCl}$ groups, $\mathrm{SiF}$ groups do not react with $\mathrm{O}_{2}$ and $\mathrm{H}_{2} \mathrm{O}$ to form $\mathrm{F}_{2}$ and $\mathrm{HF}$ molecules, respectively. ${ }^{56)}$ Furthermore, formation of fluorine atoms $\left(\mathrm{F}^{0}\right)$ via the cleavage of $\mathrm{Si}-\mathrm{F}$ bonds has not been observed. ${ }^{15)}$

\section{Interstitial hydrogenous species}

Silica glass is a low density oxide $\left(2.2 \mathrm{~g} \mathrm{~cm}^{-3}\right)$ compared to the related crystalline form of silica (e.g. $\alpha$-quartz, $2.65 \mathrm{~g}$ $\mathrm{cm}^{-3}$ ) and other light metal oxides of analogous formular weight (e.g. $\mathrm{MgO}, 3.6 \mathrm{~g} \mathrm{~cm}^{-3} ; \mathrm{Al}_{2} \mathrm{O}_{3}, 3.97 \mathrm{~g} \mathrm{~cm}^{-3}$ ). Hence, it contains a lot of interstitial voids that enable dissolution and diffusion of small chemical species. ${ }^{57), 58)}$ These interstitial chemical species often play a key role in photochemical reactions in silica glasses. Reactions involving interstitial hydrogenous species are particularly important because they are mobile and reactive at room temperature.

Interstitial hydrogen in silica glass includes hydrogen atom $\left(\mathrm{H}^{0}\right)$ and molecule $\left(\mathrm{H}_{2}\right) . \mathrm{H}^{0}$ is paramagnetic and detectable by EPR. It is a transient species created mainly by the cleavage of $\mathrm{SiO}-\mathrm{H}$ and $\mathrm{Si}-\mathrm{H}$ bonds [Eqs. (2) and (3) ]. It becomes mobile in silica glass above $\sim 50 \mathrm{~K},{ }^{34), 35), 59)}$ and quickly disappears above $\sim 160 \mathrm{~K}$ through dimerization or reactions with other chemical species. Interstitial $\mathrm{H}_{2}$ originates from glass manufacturing in oxygen-hydrogen combustion flame, ${ }^{34), 35)}$ dimerization of $\mathrm{H}^{0} \mathrm{~s},{ }^{34), 35), 60)}$ and thermal annealing in $\mathrm{H}_{2}$ atmosphere. ${ }^{61), 62)}$ It becomes mobile in silica glass above $\sim 200 \mathrm{~K}^{34), 35), 60), 63), 64)}$ Diffusion coefficients of $\mathrm{H}^{0}$ and $\mathrm{H}_{2}$ in silica glass are summarized in Fig. 4. ${ }^{35)}$ Since $\mathrm{H}^{0}$ and $\mathrm{H}_{2}$ migrate through interstitial voids of various sizes and shapes, the diffusion coefficients are significantly distributed.

Because of the large mobility and reactivity at room temperature, $\mathrm{H}^{0}$ and $\mathrm{H}_{2}$ are involved in various photochemical reactions, although they do not exhibit optical absorption within the band gap of silica glass. They convert $E^{\prime}$ centers to $\mathrm{SiH}$ groups, ${ }^{65)-74)}$

$$
\begin{aligned}
& \equiv \mathrm{Si}^{\bullet}+\mathrm{H}^{0} \longrightarrow \equiv \mathrm{SiH}, \\
& \equiv \mathrm{Si}^{\bullet}+\mathrm{H}_{2} \longrightarrow \equiv \mathrm{SiH}+\mathrm{H}^{0},
\end{aligned}
$$

and transform NBOHCs into $\mathrm{SiOH}$ groups, ${ }^{34), 35), 60), 65)-67), 69), 72) ~}$

$$
\begin{aligned}
& \equiv \mathrm{SiO}^{\bullet}+\mathrm{H}^{0} \longrightarrow \equiv \mathrm{SiOH}, \\
& \equiv \mathrm{SiO}^{\bullet}+\mathrm{H}_{2} \longrightarrow \equiv \mathrm{SiOH}+\mathrm{H}^{0} .
\end{aligned}
$$

On the other hand, possible formation of $E^{\prime}$ centers via the cracking of $\mathrm{SiH}$ groups by $\mathrm{H}^{0}$,

$$
\equiv \mathrm{SiH}+\mathrm{H}^{0} \longrightarrow \equiv \mathrm{Si}^{\bullet}+\mathrm{H}_{2},
$$

is suggested. ${ }^{72)}$ A similar reaction, cracking of $\mathrm{SiCl}$ groups by $\mathrm{H}^{0}$ [Eq. (6) ], is observed in $\mathrm{F}_{2}$-laser-irradiated silica glasses containing both $\mathrm{SiCl}$ and $\mathrm{SiOH}$ groups. ${ }^{47)}$

Other significant reactions include cracking of $\mathrm{Si}-\mathrm{O}$ bonds with mobile hydrogen. Interstitial $\mathrm{H}_{2}$ slowly dissociates $\mathrm{Si}-\mathrm{O}-\mathrm{Si}$ bonds in silica glass, ${ }^{75)-78)}$

$$
\equiv \mathrm{Si}-\mathrm{O}-\mathrm{Si} \equiv+\mathrm{H}_{2} \longrightarrow \equiv \mathrm{SiOH}+\mathrm{HSi} \equiv .
$$



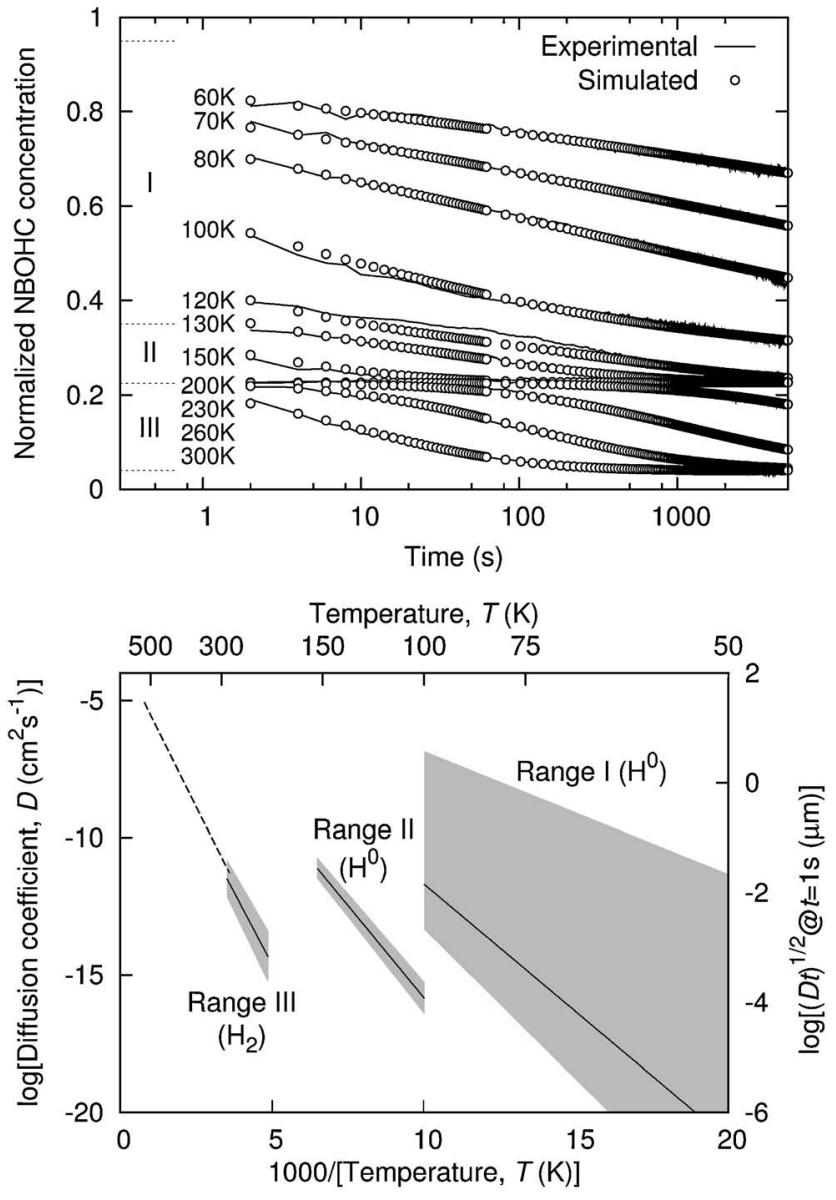

Fig. 4. (Top) Time-dependent decay of the normalized NBOHC concentration in silica glasses containing $\mathrm{SiOH}$ groups and exposed to a single $\mathrm{F}_{2}$ laser pulse at $t=0 \mathrm{~s} .^{34), 35)} \mathrm{NBOHCs}$ are generated by the $\mathrm{F}_{2}$ laser photolysis of $\mathrm{SiO}-\mathrm{H}$ bonds [Eq. (2)], and subsequently annihilated by recombinations with $\mathrm{H}^{0}$ [Eq. (9)] and $\mathrm{H}_{2}$ [Eq. (10)]. $\mathrm{H}_{2}$ molecules are formed by the dimerization of $\mathrm{H}^{0} \mathrm{~s}$. Open symbols denote simulated decay curves, calculated based on the diffusionlimited reaction theory with considering distributions in diffusion activation energies of $\mathrm{H}^{0}$ and $\mathrm{H}_{2}$. Ranges I, II, and III are due to reactions with free $\mathrm{H}^{0}$, trapped $\mathrm{H}^{0}$, and $\mathrm{H}_{2}$, respectively. (Bottom) Arrhenius plots of the diffusion coefficients of $\mathrm{H}^{0}$ and $\mathrm{H}_{2}$ evaluated from the diffusion-limited recombination with NBOHCs. ${ }^{35)}$ The diffusion coefficients are distributed because of the structural disorder of silica glass (see Fig. 2). The diffusion coefficients at the distribution maxima correspond to solid lines and those between the two half maximum points define the shaded areas. The diffusion coefficient of $\mathrm{H}_{2}$ obtained by this method agrees well with those determined by the permeation method at high temperatures (dashed line). The right ordinate denotes the approximate diffusion distance during $1 \mathrm{~s}$, given by $\sqrt{D t}$.

Formation of $\mathrm{SiOH}$ groups by this mechanism is responsible for the "hydrogen corrosion" problem in optical telecommunication fibers. ${ }^{64), 79)-82)}$ The cracking reaction is modified when the glass network is photoexcited: besides reaction Eq. $(12)^{83), 84)}$ photoexcited $\mathrm{Si}-\mathrm{O}-\mathrm{Si}$ bonds are reduced to $\mathrm{Si}-\mathrm{Si}$ bonds, ${ }^{85)}$

$$
\equiv \mathrm{Si}-\mathrm{O}-\mathrm{Si} \equiv+\mathrm{H}_{2} \stackrel{h v}{\longrightarrow} \equiv \mathrm{Si}-\mathrm{Si} \equiv+\mathrm{H}_{2} \mathrm{O} .
$$

$\mathrm{Si}-\mathrm{Si}$ bonds exhibit an intense absorption band at $7.6 \mathrm{eV}^{86)-88)}$ and significantly decrease the VUV transmittance of silica glass. Furthermore, reaction Eq. (13) is accompanied by formation of macroscopic cracks, ${ }^{89)}$ which occurs probably due to stress corrosion ${ }^{90), 91)}$ of the silica network by the resultant $\mathrm{H}_{2} \mathrm{O}$. In silica glasses containing $\mathrm{SiOH}$ groups and exposed to $\mathrm{F}_{2}$ laser light at $77 \mathrm{~K}, \mathrm{H}^{0}$ s generated by reaction Eq. (2) have a long life time and they cleave photoexcited $\mathrm{Si}-\mathrm{O}-\mathrm{Si}$ bonds $\mathrm{as}^{92,93)}$

$$
\begin{aligned}
& \equiv \mathrm{Si}-\mathrm{O}-\mathrm{Si} \equiv+\mathrm{H}^{0} \stackrel{h v}{\stackrel{h v}{h}} \equiv \mathrm{SiH}+\cdot{ }^{\cdot} \mathrm{OSi} \equiv, \\
& \equiv \mathrm{Si}-\mathrm{O}-\mathrm{Si} \equiv+\mathrm{H}^{0} \stackrel{\mathrm{C}}{\longrightarrow} \equiv \mathrm{SiOH}+{ }^{\bullet} \mathrm{Si} \equiv .
\end{aligned}
$$

Concentrations of persistent $E^{\prime}$ centers and NBOHCs created by reactions Eqs. (14) and (15) are one order of magnitude larger than those formed by room temperature irradiations.

\section{Point defect control to improve deep-ultraviolet and vacuum-ultraviolet transparency}

In the previous sections structures and properties of point defects found in commercial synthetic silica glasses are described. To obtain better transmittance and hardness to DUV-VUV light, it is necessary to optimize the type and concentrations of point defects, because some defects have positive effects in improving the DUV-VUV optical properties of silica glasses. Two examples, incorporation of network modifiers and optimal loading with interstitial $\mathrm{H}_{2}$, are described..$^{2,94)}$

As described in Sec. 2 A, strained $\mathrm{Si}-\mathrm{O}-\mathrm{Si}$ bonds arising from the distribution of the $\mathrm{Si}-\mathrm{O}-\mathrm{Si}$ angle cause the VUV optical loss near the absorption edge and become a major source of the radiation-induced point defects. Thus, the strained $\mathrm{Si}-\mathrm{O}-\mathrm{Si}$ bonds must be removed to improve the transmittance and radiation hardness of silica glass. A possible approach is to relax the glass structure by thermal annealing at low temperatures ("physical annealing"). However, this method is not practical because the structural relaxation takes a long time at low temperatures because of a large activation energy of viscous flow $(\sim 5 \mathrm{eV}) .{ }^{95)-97)}$

A promising way to eliminate the strained $\mathrm{Si}-\mathrm{O}-\mathrm{Si}$ bonds is to incorporate network modifiers such as $\mathrm{SiF}, \mathrm{SiCl}$, $\mathrm{SiOH}$, and $\mathrm{SiH}$ groups that dissociate $\mathrm{Si}-\mathrm{O}-\mathrm{Si}$ glass network ("chemical annealing"). These functional groups reduce the viscosity, ${ }^{95)}$ facilitating the the structural relaxation. ${ }^{98), 99)}$ Both $\mathrm{SiOH}$ and $\mathrm{SiCl}$ groups exhibit optical absorption only above $\sim 7 \mathrm{eV}$ (Sec. 2 B), and can be used to improve radiation hardness of silica glasses against $\mathrm{KrF}$ and ArF lasers. ${ }^{53), 100)}$ Nevertheless, excess incorporation of these functional groups would be unfavorable, ${ }^{2)}$ because they participate in various defect processes described in Sec. 2 B, which can be caused by two photon absorption of $\mathrm{KrF}$ and ArF laser light. Silica glasses containing $\mathrm{SiOH}$ and $\mathrm{SiCl}$ groups are not transparent above $\sim 7-7.5 \mathrm{eV}$. The best choice in this spectral range is silica glasses doped with $\mathrm{SiF}$ groups, which are quite stable and transparent below $\sim 8 \mathrm{eV}$ (Sec. 2 B). As shown in Fig. 5, the transparency near the VUV absorption edge is improved only by a small amount of $\mathrm{SiF}$ groups $(\leqslant 1-0.1 \%)$, whereas further fluorine doping is insignificant for the improvement. $^{2), 55), 101), 102)}$ Thus, the main reason for the increase in the VUV transparency is evidently the structural relaxation, and is not the simple band gap widening that is expected to be proportional to the fluorine concentration. Silica glasses containing $\mathrm{SiH}$ groups may also be usable above $\sim 7-7.5 \mathrm{eV}$ but the possible radiation-induced cleavage of $\mathrm{Si}-\mathrm{H}$ bonds [Eq. (3) ] can be problematic.

Another key factor is the presence of interstitial $\mathrm{H}_{2}$. Figure 6 shows effects of $\mathrm{H}_{2}$ loading on optical absorption induced by $\mathrm{ArF}$ or $\mathrm{F}_{2}$ laser light. $\mathrm{H}_{2}$ loading is quite important in maintaining the transparency of silica glasses at $\sim 4.7$ $\mathrm{eV}^{39), 65), 69), 103), 104)}$ because interstitial $\mathrm{H}_{2}$ removes $E^{\prime}$ centers 


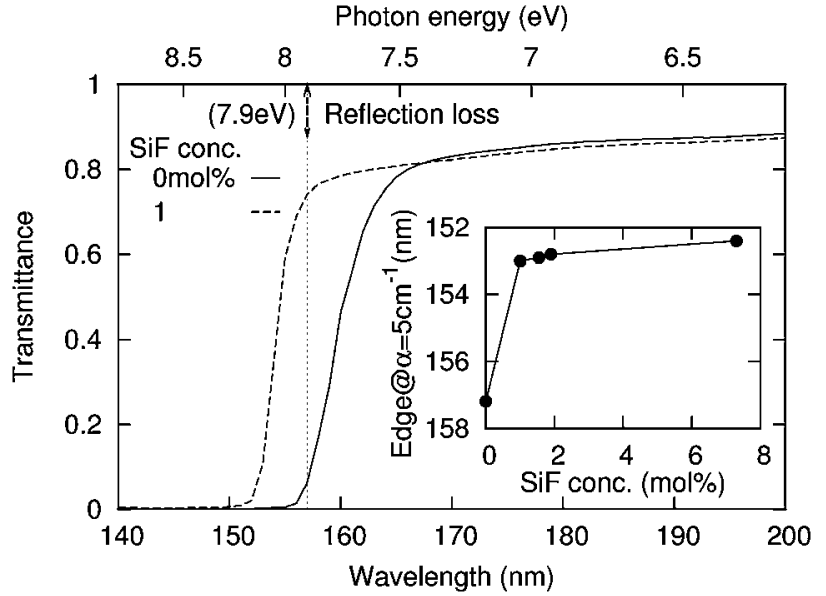

Fig. 5. Transmission spectra of $5 \mathrm{~mm}$-thick SiF-free and $1 \mathrm{~mol} \%$ $\mathrm{SiF}$-doped silica glasses. The inset shows relation between the location of the VUV absorption "edge" (wavelength at which the absorption coefficient reaches $5 \mathrm{~cm}^{-1}$ ) and the $\mathrm{SiF}$ content. ${ }^{101)}$

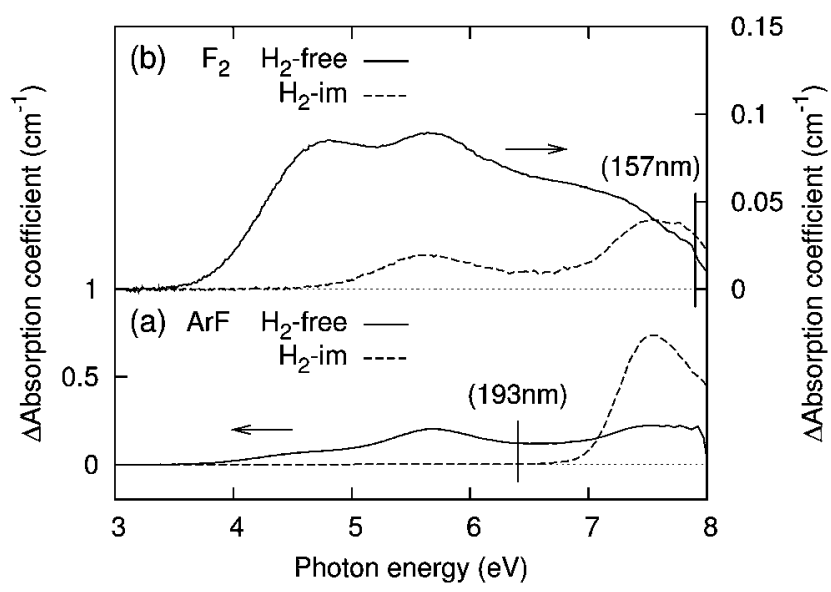

Fig. 6. Effects of $\mathrm{H}_{2}$ loading on photoinduced absorption in an SiFfree, $\mathrm{SiOH}$-doped silica glass exposed to $\mathrm{ArF}$ laser light $\left(10^{7}\right.$ pulses at $\sim 30 \mathrm{~m} \mathrm{~J} \mathrm{~cm}^{-2}$ pulse $^{-1}$ ) (a), and in an SiF-doped, $\mathrm{SiOH}$-free silica glass exposed to $F_{2}$ laser light $\left(2.88 \times 10^{6}\right.$ pulses at $\sim 6 \mathrm{~mJ} \mathrm{~cm}^{-2}$ pulse $\mathrm{s}^{-1}$ (b). ${ }^{85)}$

and NBOHCs that dominate the optical absorption in this spectral range $\left[\right.$ Sec. 2 C, Eqs. (7)-(10)]. In contrast, $\mathrm{H}_{2}$ loading enhances the formation of $\mathrm{Si}-\mathrm{Si}$ bonds [Eq. (13)] and it is detrimental for applications above $\sim 7 \mathrm{eV}$. Thus, the concentration of interstitial $\mathrm{H}_{2}$ needs to be optimized depending on the application of silica glasses.

\section{Practical applications}

\section{A. Silica glasses for $F_{2}$ laser photolithography}

In the initial development state of $\mathrm{F}_{2}$ laser photolithography, silica glass was not thought to be transparent enough for $\mathrm{F}_{2}$ laser light. ${ }^{105)}$ However, as described in previous sections, optical loss at $7.9 \mathrm{eV}$ is not due to the intrinsic interband transition, but mainly due to point defects such as $\mathrm{SiOH}$ groups, $\mathrm{Si}-\mathrm{Si}$ bonds and strained $\mathrm{Si}-\mathrm{O}-\mathrm{Si}$ bonds. The concentration of these point defects is the lowest in fluorine-doped silica glasses. Indeed, fluorine-doped silica glasses show good $7.9 \mathrm{eV}$ transparency. To suppress the photoinduced formation of $\mathrm{Si}-\mathrm{Si}$ bonds $\mathrm{H}_{2}$ loading is not performed. This type of silica

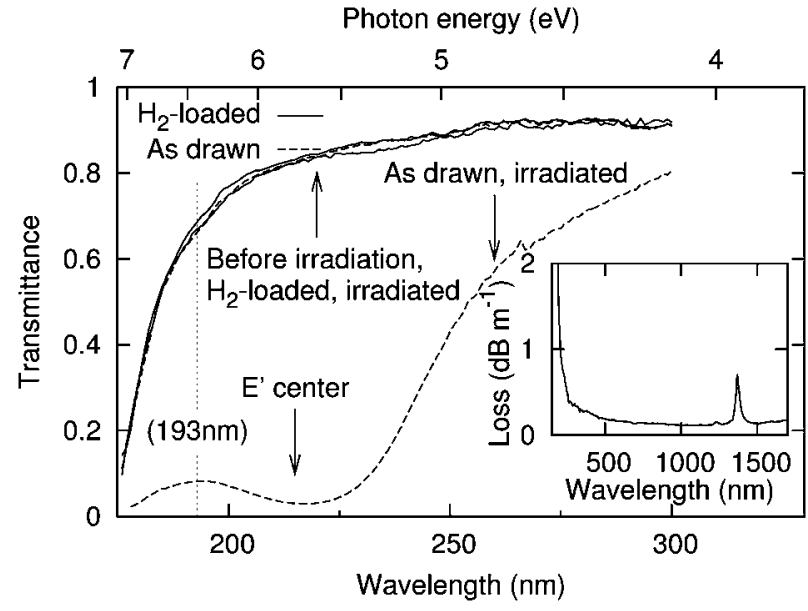

Fig. 7. Transmission spectra of as-drawn and $\mathrm{H}_{2}$-loaded DUV optical fibers, before and after exposure to ArF laser light $\left(10^{5}\right.$ pulses at $\sim 50 \mathrm{~mJ} \mathrm{~cm}^{-2}$ pulse $^{-1}$ ). The inset shows the optical loss spectrum of a DUV optical fiber. ${ }^{73)}$

glass, which is often termed "modified silica," is suitable for photomask substrates in $\mathrm{F}_{2}$ laser photolithography. ${ }^{106), 107)}$

\section{B. Deep-ultraviolet optical fibers}

DUV-VUV optical fibers are one of the best uses of silica glass, which is of good DUV-VUV transparency and shape workability. However, conventional optical telecommunication fibers are not DUV transparent because of the optical absorption associated with metal cations (e.g. Ge) intentionally added to the fiber core to increase the refractive index. It is also necessary to remove strained $\mathrm{Si}-\mathrm{O}-\mathrm{Si}$ bonds and dangling bonds, which are generated by the large deformation at high temperature and are subsequently frozen in the resultant fibers by rapid quenching. Furthermore, transmittance of optical fibers with long optical path lengths is easily degraded even by a small amount of point defects. These factors make it difficult to develop optical fibers of good DUV-VUV transparency.

These problems can be solved by fluorine doping and $\mathrm{H}_{2}$ loading. Viscosity reduction by the fluorine doping is effective in enhancing the structural relaxation to suppress the formation of drawing-induced defects and strained $\mathrm{Si}-\mathrm{O}-\mathrm{Si}$ bonds. In addition, since the fluorine doping decreases the refractive index, the core-cladding interface is formed by incorporating much more $\mathrm{SiF}$ groups in the cladding than in the core. $\mathrm{H}_{2}$ loading to the resultant fiber is effective in maintaining the DUV transparency, because $\mathrm{H}_{2}$ quickly terminates $E^{\prime}$ centers [Eqs. (7), (8)], which are the main radiation-induced point defects in this type of fibers. As shown in Fig. 7, a DUV optical fiber developed in this way exhibits a good transmittance and hardness to $\mathrm{ArF}$ laser light $(T \sim 70 \%$ at $h v=6.4$ eV). ${ }^{73), 108)}$ In addition, this optical fiber shows good transparency from near IR to DUV spectral region, which is quite attractive for various spectroscopic applications.

\section{Summary}

Influence of point defects on deep-ultraviolet (DUV) and vacuum-ultraviolet (VUV) transparency of synthetic silica glass is described. Strained $\mathrm{Si}-\mathrm{O}-\mathrm{Si}$ bonds decrease transparency near the absorption edge and radiation hardness to DUV-VUV laser light. Doping with network modifiers that relax the glass structure is effective in eliminating the strained $\mathrm{Si}-\mathrm{O}-\mathrm{Si}$ bonds. Interstitial hydrogen molecules $\left(\mathrm{H}_{2}\right)$ are use- 
ful in removing photoinduced dangling bonds. However, they enhance the formation of oxygen vacancies by photoreducing the silica network. Consequently, fluorine-doped $\mathrm{H}_{2}$-free silica glass is the best choice at photon energies $\gtrsim 7 \mathrm{eV}$, whereas network-modified $\mathrm{H}_{2}$-loaded silica glasses give better results at $\lesssim 7 \mathrm{eV}$. These findings make it possible to develop photomask substrates for $\mathrm{F}_{2}$ laser $(h v=7.9 \mathrm{eV})$ photolithography and DUV optical fibers for ArF laser $(h v=6.4 \mathrm{eV})$ transmission.

Acknowledgements The author wishes to express his gratitude to Professor Hideo Hosono and Professor Masahiro Hirano (Tokyo Institute of Technology and Japan Science and Technology Agency), Dr. Linards Skuja (University of Latvia), Dr Yoshiaki Ikuta (Asahi Glass Co., Ltd.), and Dr. Masanori Oto (Syowa Divice Technology Co., Ltd.) for their continuous support and contribution to the present work.

\section{References}

1) Griscom, D. L., J. Ceram. Soc. Japan, Vol. 99, pp. 923-942 (1991).

2) Skuja, L., Hosono, H., Hirano, M. and Kajihara, K., Proc. SPIE, Vol. 5122, pp. 1-14 (2003)

3) Mozzi, R. L. and Warren, B. E., J. Appl. Cryst., Vol. 2, pp. 164-172 (1969).

4) Dupree, R. and Pettifer, R. F., Nature, Vol. 308, pp. 523-525 (1984).

5) Mukhopadhyay, S., Sushko, P. V., Stoneham, A. M. and Shluger, A. L., Phys. Rev. B, Vol. 70, 195203 (2004).

6) Sushko, P. V., Mukhopadhyay, S., Mysovsky, A. S., Vladimir, B., Sulimov, A. T. and Shluger1, A. L., J. Phys. Condens. Matter., Vol. 17, pp. S2115-S2140 (2005).

7) Godmanis, I. T., Trukhin, A. N. and Hübner, K., Phys. Status Solidi B, Vol. 116, pp. 279-287 (1983).

8) Kitamura, N., Fukumi, K., Kadono, K., Yamashita, H. and Suito, K., Phys. Rev. B, Vol. 50, pp. 132-135 (1994).

9) Devine, R. A. B. and Arndt, J., Phys. Rev. B, Vol. 35, pp. 9376-9379 (1987)

10) Geissberger, A. E. and Galeener, F. L., Phys. Rev. B, Vol. 28, pp. 3266-3271 (1983)

11) Hosono, H., Ikuta, Y., Kinoshita, T., Kajihara, K. and Hirano, M., Phys. Rev. Lett., Vol. 87, 175501 (2001).

12) Galeener, F. L., J. Non-Cryst. Solids, Vol. 49, pp. 53-62 (1982).

13) Devine, R. A. B. and Arndt, J., Phys. Rev. B, Vol. 39, pp. 5132-5137 (1989).

14) Devine, R. A. B. and Arndt, J., Phys. Rev. B, Vol. 42, pp. 2617-2620 (1990)

15) Arai, K., Imai, H., Isoya, J., Hosono, H., Abe, Y. and Imagawa, H., Phys. Rev. B, Vol. 45, pp. 10818-10821 (1992).

16) Galeener, F. L., Kerwin, D. B., Miller, A. J. and Mikkelsen, J. C., Jr., Phys. Rev. B, Vol. 47, pp. 7760-7779 (1993).

17) Devine, R. A. B., Phys. Rev. B, Vol. 35, pp. 9783-9789 (1987).

18) Kajihara, K., Ikuta, Y., Hirano, M. and Hosono, H., Appl. Phys. Lett., Vol. 81, pp. 3164-3166 (2002).

19) Kajihara, K., Ikuta, Y., Hirano, M. and Hosono, H., J. NonCryst. Solids, Vol. 322, pp. 73-77 (2003).

20) Hosono, H., Kajihara, K., Suzuki, T., Ikuta, Y., Skuja, L. and Hirano, M., Solid State Commun., Vol. 122, pp. 117-120 (2002).

21) Cannas, M. and Gelardi, F. M., Phys. Rev. B, Vol. 69, 153201 (2004).

22) Suzuki, T., Skuja, L., Kajihara, K., Hirano, M., Kamiya, T. and Hosono, H., Phys. Rev. Lett., Vol. 90, 186404 (2003).

23) Walrafen, G. E. and Samanta, S. R., J. Chem. Phys., Vol. 69 , pp. 493-495 (1978)

24) Davis, K. M. and Tomozawa, M., J. Non-Cryst. Solids, Vol 201, pp. 177-198 (1996).

25) Kajihara, K., Hirano, M., Skuja, L. and Hosono, H., J. NonCryst. Solids, Vol. 352, pp. 2307-2310 (2006).
26) Kajihara, K., Ikuta, Y., Hirano, M., Ichimura, T. and Hosono, H., J. Chem. Phys., Vol. 115, pp. 9473-9476 (2001).

27) Shelby, J. E., J. Non-Cryst. Solids, Vol. 179, pp. 138-147 (1994).

28) Kakiuchida, H., Saito, K. and Ikushima, A. J., Jpn. J. Appl. Phys., Vol. 41, pp. 2993-2998 (2002).

29) Imai, H., Arai, K., Saito, T., Ichimura, S., Nonaka, H., Vigouroux, J. P., Imagawa, H., Hosono, H. and Abe, Y., "The Physics and Technology of Amorphous $\mathrm{SiO}_{2}$, " Ed. by Devine, R. A. B., Plenum Press, New York (1988) pp. 153-159.

30) Awazu, K. and Kawazoe, H., J. Non-Cryst. Solids, Vol. 179, pp. 214-225 (1994).

31) Morimoto, Y., Nozawa, S. and Hosono, H., Phys. Rev. B, Vol. 59, pp. 4066-4073 (1999)

32) Kajihara, K., Hirano, M., Skuja, L. and Hosono, H., Phys. Rev. B, Vol. 72, 214112 (2005).

33) Kajihara, K., Skuja, L., Hirano, M. and Hosono, H., Appl. Phys. Lett., Vol. 79, pp. 1757-1759 (2001).

34) Kajihara, K., Skuja, L., Hirano, M. and Hosono, H., Phys. Rev. Lett., Vol. 89, 135507 (2002).

35) Kajihara, K., Skuja, L., Hirano, M. and Hosono, H., Phys. Rev. B, Vol. 74, 094202 (2006).

36) Imai, H., Arai, K., Hosono, H., Abe, Y., Arai, T. and Imagawa, H., Phys. Rev. B, Vol. 44, pp. 4812-4818 (1991).

37) Pacchioni, G. and Ieranó, G., Phys. Rev. B, Vol. 57, pp. 818-832 (1998).

38) Skuja, L., Kajihara, K., Hirano, M. and Hosono, H., J. NonCryst. Solids (in press).

39) Smith, C. M., Borrelli, N. F. and Araujo, R. J., Appl. Opt., Vol. 39, pp. 5778-5784 (2000).

40) Ikuta, Y., Kikugawa, S., Hirano, M. and Hosono, H., Proc. SPIE, Vol. 4347, pp. 187-194 (2001).

41) Messina, F. and Cannas, M., J. Phys. Condens. Matter., Vol. 17, pp. 3837-3842 (2005).

42) Youngman, R. E. and Sen, S., J. Non-Cryst. Solids, Vol. 337, pp. 182-186 (2004).

43) Dumas, P., Corset, J., Carvalho, W., Levy, Y. and Neuman, Y., J. Non-Cryst. Solids, Vol. 47, pp. 239-242 (1982).

44) Dumas, P., Corset, J., Levy, Y. and Newman, V., J. Raman Spectrosc., Vol. 13, pp. 134-138 (1982).

45) Mulder, C. A. M., J. Non-Cryst. Solids, Vol. 95 \& 96, pp. 303-310 (1987).

46) Awazu, K., Kawazoe, H. and Muta, K., J. Appl. Phys., Vol. 69, pp. 4183-4186 (1991).

47) Kajihara, K., Hirano, M., Skuja, L. and Hosono, H., J. Appl. Phys., Vol. 98, 043515 (2005).

48) Imai, H. and Hirashima, H., J. Non-Cryst. Solids, Vol. 179, pp. 202-213 (1994).

49) Kawaguchi, Y. and Kuzuu, N., J. Appl. Phys., Vol. 80, pp. 5633-5638 (1996).

50) Nishikawa, H., Nakamura, R., Ohki, Y., Nagasawa, K. and Hama, Y., Phys. Rev. B, Vol. 46, pp. 8073-8079 (1992).

51) Griscom, D. L. and Friebele, E. J., Phys. Rev. B, Vol. 34, pp. 7524-7533 (1986).

52) Awazu, K., Kawazoe, H., Muta, K., Ibuki, T., Tabayashi, K. and Shobatake, K., J. Appl. Phys., Vol. 69, pp. 1849-1852 (1991).

53) Kuzuu, N., Taga, T. and Kamisugi, N., J. Appl. Phys., Vol. 81, pp. 8011-8017 (1997).

54) Kyoto, M., Ohoga, Y., Ishikawa, S. and Ishiguro, Y., J. Mater. Sci., Vol. 28, pp. 2738-2744 (1993).

55) Skuja, L., Kajihara, K., Ikuta, Y., Hirano, M. and Hosono, H., J. Non-Cryst. Solids, Vol. 345 \& 346, pp. 328-331 (2004).

56) Kajihara, K., Hirano, M., Skuja, L. and Hosono, H., J. NonCryst. Solids (in press).

57) Doremus, R. H., "Diffusion of Reactive Molecules in Solids and Melts," John Wiley \& Sons, New York (2002).

58) Shelby, J. E., "Handbook of Gas Diffusion in Solids and Melts," ASM International, Materials Park (1996).

59) Brower, K. L., Lenahan, P. M. and Dressendorfer, P. V., 
Appl. Phys. Lett., Vol. 41, pp. 251-253 (1982).

60) Griscom, D. L., J. Non-Cryst. Solids, Vol. 68, pp. 301-325 (1984).

61) Shackelford, J. F., Studt, P. L. and Fulrath, R. M., J. Appl. Phys., Vol. 43, pp. 1619-1626 (1972).

62) Hartwig, C. M., J. Chem. Phys., Vol. 47, pp. 956-958 (1976).

63) Shelby, J. E., J. Appl. Phys., Vol. 48, pp. 3387-3394 (1977).

64) Noguchi, K., Shibata, N., Uesugi, N. and Negishi, Y., J. Lightwave Technol., Vol. LT-3, pp. 236-243 (1985).

65) Faile, S. P. and Roy, D. M., Mater. Res. Bull., Vol. 5, pp. 385-389 (1970).

66) Hartwig, C. M., J. Chem. Phys., Vol. 66, pp. 227-238 (1977).

67) Shelby, J. E., J. Appl. Phys., Vol. 50, pp. 3702-3706 (1979).

68) Li, Z., Fonash, S. J., Poindexter, E. H., Harmatz, M., Rong, F. and Buchwald, W. R., J. Non-Cryst. Solids, Vol. 126, pp. 172-176 (1990).

69) Yamagata, S., Miner. J., Vol. 15, pp. 333-342 (1991).

70) Radzig, V. A., Bagratashvili, V. N., Tsypina, S. I., Chernov, P. V. and Rybaltovskii, A. O., J. Phys. Chem., Vol. 99, pp. 6640-6647 (1995)

71) Edwards, A. H., J. Non-Cryst. Solids, Vol. 187, pp. 232-243 (1995).

72) Vitiello, M., Lopez, N., Illas, F. and Pacchioni, G., J. Phys. Chem. A, Vol. 104, pp. 4674-4684 (2000).

$73)$ Oto, M., Kikugawa, S., Sarukura, N., Hirano, M. and Hosono, H., IEEE Photon. Technol. Lett., Vol. 13, pp. 978-980 (2001).

74) Cannas, M., Costa, S., Boscaino, R. and Gelardi, F. M., J. Non-Cryst. Solids, Vol. 337, pp. 9-14 (2004).

75) Faile, S. P. and Roy, D. M., J. Am. Ceram. Soc., Vol. 54, pp. 533-534 (1971).

76) Bell, T., Hetherington, G. and Jack, K. H., Phys. Chem. Glasses, Vol. 3, pp. 141-146 (1962).

77) Wiesenfeld, J. M., Stone, J., Marcuse, D., Burrus, C. A. and Yang, S., J. Appl. Phys., Vol. 61, pp. 5447-5454 (1987).

78) Schmidt, B. C., Holtz, F. M. and Beny, J.-M., J. Non-Cryst. Solids, Vol. 240, pp. 91-103 (1998).

79) Mochizuki, K., Namihira, Y. and Yamamoto, H., Electron. Lett., Vol. 19, pp. 743-745 (1983).

80) Uesugi, N., Murakami, Y., Tanaka, C., Ishida, Y., Mitsunaga, Y., Negishi, Y. and Uchida, N., Electron. Lett., Vol. 19, pp. 762-764 (1983).

81) Tanifuji, T., Matsumoto, M., Tokuda, M. and Miyauchi, M., Electron. Lett., Vol. 20, pp. 13-14 (1984).

82) Stone, J., J. Lightwave Technol., Vol. LT-5, pp. 712-733 (1987).

83) Mizuguchi, M., Skuja, L., Hosono, H. and Ogawa, T., Opt. Lett., Vol. 24, pp. 863-865 (1999).

84) Nishii, J., Kintaka, K., Nishiyama, H., Sano, T., Ohmura, E. and Miyamoto, I., Appl. Phys. Lett., Vol. 81, pp. 2364-2366 (2002).

85) Ikuta, Y., Kajihara, K., Hirano, M., Kikugawa, S. and
Hosono, H., Appl. Phys. Lett., Vol. 80, pp. 3916-3918 (2002).

86) Imai, H., Arai, K., Imagawa, H., Hosono, H. and Abe, Y., Phys. Rev. B, Vol. 38, pp. 12772-12775 (1988).

87) Hosono, H., Abe, Y., Imagawa, H., Imai, H. and Arai, K., Phys. Rev. B, Vol. 44, pp. 12043-12045 (1991).

88) Mukhopadhyay, S., Sushko, P. V., Stoneham, A. M. and Shluger, A. L., Phys. Rev. B, Vol. 71, 235204 (2005).

89) Ikuta, Y., Kajihara, K., Hirano, M. and Hosono, H., Appl. Opt., Vol. 43, pp. 2332-2336 (2004).

90) Michalske, T. A. and Freiman, S. W., J. Am. Ceram. Soc., Vol. 66, pp. 284-288 (1983).

91) Bunker, B. C., J. Non-Cryst. Solids, Vol. 179, pp. 300-308 (1994).

92) Skuja, L., Kajihara, K., Hirano, M. and Hosono, H., Proceedings of the 20th International Congress on Glass, Kyoto (2004) O-14-052.

93) Skuja, L., Kajihara, K., Hirano, M., Saitoh, A. and Hosono, H., J. Non-Cryst. Solids, Vol. 352, pp. 2297-2302 (2006).

94) Kajihara, K., Ikuta, Y., Oto, M., Hirano, M., Skuja, L. and Hosono, H., Nucl. Instrum. Methods Phys. Res. B, Vol. 218, pp. 323-331 (2004).

95) Hetherington, G., Jack, K. H. and Kennedy, J. C., Phys. Chem. Glasses, Vol. 5, pp. 130-136 (1964).

96) Mikkelsen, J. C., Jr. and Galeener, F. L., J. Non-Cryst. Solids, Vol. 37, pp. 71-84 (1980).

97) Kakiuchida, H., Saito, K. and Ikushima, A. J., J. Appl. Phys., Vol. 93, pp. 777-779 (2003).

98) Saito, K. and Ikushima, A. J., Appl. Phys. Lett., Vol. 73, pp. 1209-1211 (1998).

99) Ikushima, A. J., Fujiwara, T. and Saito, K., J. Appl. Phys., Vol. 88, pp. 1201-1213 (2000).

100) Shimbo, M. and Sato, K., Jpn. J. Appl. Phys., Vol. 34, pp. 5640-5643 (1995).

101) Hosono, H. and Ikuta, Y., Nucl. Instrum. Methods Phys. Res. $B$, Vol. 166-167, pp. 691-697 (2000).

102) Saito, K. and Ikushima, A. J., J. Appl. Phys., Vol. 91, pp. 4886-4890 (2002).

103) Sempolinski, D. R., Seward, T. P., Smith, C., Borrelli, N. and Rosplock, C., J. Non-Cryst. Solids, Vol. 203, pp. 69-77 (1996).

104) Shimbo, M., Nakajima, T., Tsuji, N., Kakuno, T. and Obara, T., Jpn. J. Appl. Phys., Vol. 38, pp. L848-L850 (1999).

105) Bloomstein, T. M., Horn, M. W., Rothschild, M., Kunz, R. R., Palmacci, S. T. and Goodman, R. B., J. Vac. Sci. Technol. B, Vol. 15, pp. 2112-2116 (1997).

106) Hosono, H., Mizuguchi, M., Kawazoe, H. and Ogawa, T., Appl. Phys. Lett., Vol. 74, pp. 2755-2757 (1999).

107) Mizuguchi, M., Skuja, L., Hosono, H. and Ogawa, T., J. Vac. Sci. Technol. B, Vol. 17, pp. 3280-3284 (1999).

108) Oto, M., Kikugawa, S., Miura, T., Hirano, M. and Hosono, H., J. Non-Cryst. Solids, Vol. 349, pp. 133-138 (2004).

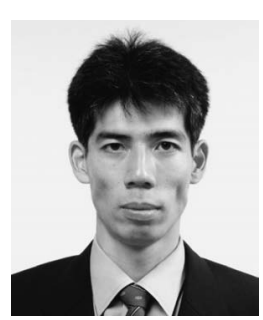

Koichi Kajihara is a researcher in Hosono Transparent Electro-Active Materials Project, ERATO-SORST, Japan Science and Technology Agency. He graduated from Kyoto University in 1994, and received his Master of Engineering degree from Kyoto University in 1996. He was a research associate of Kyoto University in 1997 to 2000 and a researcher of Japan Science and Technology Agency since 2000. He received his Doctor of Energy Science degree from Kyoto University in 2000. His research interests include phenomena associated with point defects in silica glass, photoinduced phenomena in oxides, and interactions of oxides with reactive chemical species. 